\title{
Superfícies de Contato Urbanas: Arquitetura, Espetáculo, Arte, Cidade
}

\author{
Interfaces urbanas: arquitectura, \\ espectáculo, arte, ciudad.
}

\section{Urban Interfaces: Architecture, Spectacle, Art, City}

Renata Latuf de Oliveira Sanchez Arquiteta e Urbanista. Doutoranda na FAU-USP, São Paulo,Brasil.renata.sanchez@usp.br 


\section{Resumo}

Este artigo tem como eixo central de análise o conceito de interface no contexto urbano, isto é, as superfícies de contato existentes na cidade, que se dão a partir de diferentes perspectivas, relacionadas à arquitetura, à arte e à tecnologia. Frente a um mundo cada vez mais codificado e reduzível a dados informacionais, com espaços urbanos em constante mutação e movimento, distâncias comprimidas mediadas por dispositivos eletrônicos, questiona-se como transformar uma vivência urbana tradicional e física em uma vivência mais ampla e virtual, ao mesmo tempo em que seja garantida uma ação participativa e não somente interativa. São analisados três estudos de caso de estruturas urbanas que passaram por processos de reinterpretação, a saber: a renovação urbana empreendida no High Line Park, em Nova lorque; a ideia de um parque no Minhocão, em São Paulo; e a transformação urbana promovida pela retirada do viaduto Perimetral no centro do Rio de Janeiro. Tais exemplos dão base à discussão sobre diversas formas de interação com a cidade, sob aspectos de vigilância e controle, cidade como espetáculo, fruição do espaço público, prazer e entretenimento, interação vs. participação, valor de uso vs. valor de troca.

Palavras-Chave: Cidade digital. Interface. Renovação Urbana. Espaços interativos. Espaço Urbano.

\section{Resumen}

Este artículo tiene como eje central de análisis el concepto de interfaz en el contexto urbano, es decir, las superficies de contacto existentes en la ciudad, que se dan a partir de diferentes perspectivas, relacionadas a la arquitectura, al arte ya la tecnología. Frente a un mundo cada vez más codificado y reducible a datos informativos, con espacios urbanos en constante mutación y movimiento, distancias comprimidas mediadas por dispositivos electrónicos, se cuestiona cómo transformar una vivencia urbana tradicional y física en una vivencia más amplia y virtual, al tiempo que se garantiza una acción participativa y no sólo interactiva. Se analizan tres estudios de caso de estructuras urbanas que pasaron por procesos de reinterpretación, a saber: la renovación urbana emprendida en el High Line Park de Nueva York; la idea de parque en el Minhocão, en São Paulo; y la transformación urbana promovida por la retirada del viaducto Perimetral en el centro de Río de Janeiro. Estos ejemplos dan base a la discusión sobre diversas formas de interacción con la ciudad, bajo aspectos de vigilancia y control, ciudad como espectáculo, fruición del espacio público, placer y entretenimiento, interacción vs. la participación, valor de uso vs. valor de cambio.

Palabras-Clave: Ciudad digital. Interfaz. Renovación urbana. Espacios interactivos. Espacio urbano. 


\section{Abstract}

This paper focuses its analysis on the concept of interface in the urban context, that is, the contact surfaces that exist in the city, experienced from different perspectives, related to architecture, art and technology. In face of an increasingly codified and informational-data-reducible world, with constantly changing urban spaces, compressed distances mediated by electronic devices, the question of how to transform a traditional and physical urban experience into a broader and virtual experience is crucial, while guaranteeing a participatory action instead of a merely interactive one. Three case studies of urban structures that have undergone reinterpretation processes are analysed: the urban transformation undertaken at High Line Park in New York; the idea of a park on Minhocão, in São Paulo; and the urban changes promoted by the removal of the Perimetral viaduct in the center of Rio de Janeiro. Such examples give rise to the discussion about various forms of interaction with the city, under aspects of surveillance and control, city as spectacle, public space fruition, pleasure and entertainment, interaction vs. participation, use value vs. exchange value.

Keywords: Digital city. Interface. Urban renovation. Interactive Space. Urban Space. 


\section{INTRODUÇÃO ÀS INTERFACES URBANAS}

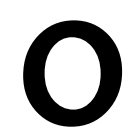

conceito de "interface", do mesmo termo em inglês que significa "superfície de contato", recebe no contexto atual novas funções e proporções, em decorrência de um "cibridismo" cada vez maior nas cidades e sociedade. Cunhado por Peter Anders, o "cibridismo" parece ser uma peçachave no entendimento de que tipo de mundo está sendo formado atualmente pelas novas tecnologias e possibilidades trazidas pelo aparato virtual. Assim, propõe-se analisar de que forma essa cultura cíbrida que invadiu as relações interpessoais e espaciais mostra-se como fenômeno no campo arquitetônico e urbano, através de alguns exemplos que aproximam a cidade e a arquitetura a essas tecnologias e a essa outra realidade.

Frente a novas formas de interação com a cidade e o espaço construído devido a um mundo cada vez mais acelerado (Virilio, 2012) e reduzível a dados informacionais, ficam as questões: como transformar uma vivência tradicional, física, em uma vivência mais ampla, virtual, expandida? Como interagir com a cidade (organismo vivo e espaço construído), levando-se em conta uma 
crescente "despersonificação" das ações, ao mesmo tempo em que essa impessoalidade leva a níveis absurdos de individualismo e à dúvida sobre uma participação efetiva no tecido urbano? Como operar no cruzamento dos dados com o espaço público ${ }^{1}$ De que modo as cidades se mostram como interface para as ações humanas? Tais perguntas evidenciam-se constantemente com o aumento do uso das tecnologias informacionais, de mecanismos de vigilância e também dos "circuitos de prazer e entretenimento" (Bruno, 2013, p. 53), que se tornam um eixo principal nas análises sobre o fenômeno arquitetônico e urbano experimentado na atualidade high-tech.

As redes sociais e aplicativos de celular parecem ser o ápice de uma geração em que a massificação ou generalização da sociedade levou, contraditoriamente, a uma sobreposição do individualismo e experiências individuais às experiências coletivas. O "eu" é movido pelo "nós" numa imbricação profunda entre o "ver e ser visto", conforme Bruno (2013).

Nessa nova escala de prazer e vivências urbanos, no espaço em constante transformação, destacam-se as performances artísticas, intervenções em fachadas cegas, além de uma dualidade entre a transformação de dados em arte e da arte em dados. Intrincada em um ambiente cíbrido e também no contexto comercial, questiona-se ainda como a arquitetura é influenciada por essa realidade expandida, como se relaciona com novos circuitos espaciais/virtuais, transformando a cidade e estabelecendo relações com os indivíduos, criando valores de uso superiores aos valores de troca (dualidade intrínseca ao espaço urbano).

Com isso em mente, escolheram-se três estudos de caso urbanos dinâmicos para avaliar as transformações em suas interfaces: o High Line Park, em Nova lorque; o Minhocão, em São Paulo; e os novos espaços propiciados pela

\footnotetext{
1 Esse questionamento foi posto por Giselle Beiguelman, Professora da FAU-USP, na disciplina "Intervenções em Redes Urbanas - Espaços Cíbridos e Expandidos na Cidade Contemporânea", lecionada em 2015. O presente trabalho é uma versão revisada do artigo entregue como trabalho final para a disciplina, nunca embora publicado.
} 
retirada do elevado da Perimetral, no Rio de Janeiro. Discute-se o entrelaçamento entre arte, imagem e cidade em tais espaços, por meio das seguintes intervenções artísticas: a performance da artista britânica Cally Spooner, no High Line Park; a instalação da arquiteta Luana Geiger e as projeções em fachadas cegas pelo "Festival Chave do Centro" no Minhocão; e o mural de grafite "Etnias", do artista Kobra. Em comum, tais casos evidenciam aspectos de realidade e virtualidade, espaços de dados e espaços construídos, o ver e ser visto, o papel do artista e espectador. Todos esses tópicos aproximam-se do entendimento da cidade como superfície de contato (interface) e, como tal, de suas relações também com o "cyberespaço".

\section{RENOVAÇÕES URBANAS E SUPERFÍCIES DE CONTATO: HIGH LINE PARK (NI), MINHOCÃO (SP) E PERIMETRAL (RJ)}

As discussões sobre os espaços urbanos coletivos ("urban commons") de David Harvey (2012) possuem relação íntima com os fenômenos observados em atuais renovações urbanas. Segundo Harvey $(2012$, p.74), na retomada da "rua" como um bem comum por prefeituras e urbanistas, estes propõem locais para pedestres, cafés nas calçadas, ciclovias, parques e "pocket parks", tentativas que, no entanto, tornam-se frequentemente capitalizadas, no que ele aponta o High Line Park como um exemplo.

Harvey critica a transformação do "valor" em um bem do capitalismo. Diz que uma comunidade que luta para manter sua diversidade étnica em um bairro e protege-lo da gentrificação pode, de repente, ver os preços de seus imóveis subirem como resultado da ação de agentes imobiliários que mercadorizam o "caráter" do bairro aos mais ricos como um local multicultural, vivo e diversificado (Harvey, 2012, p.77), citando os bairros Christiania, em Copenhagen e SOHO, em Nova lorque.

Continua dizendo que o problema não é o bem comum em si, mas as relações entre aqueles que o produzem ou capturam-no em uma variedade 
de escalas e aqueles que se apropriam dele para ganho privado. Há uma corrupção política urbana: produz-se algo que parece um "bem comum", mas que na verdade promove ganhos em ações de valores privados para proprietários privilegiados.

No seio das renovações urbanas permanece a questão da gentrificação. Como reestruturar uma área sem que a mesma sofra as influências do mercado imobiliário? Parece utopia prever que uma melhoria urbana não seria seguida de um aumento dos preços dos imóveis, causada simplesmente pela valorização do local. O desafio é como integrar essas áreas renovadas às áreas mais antigas da cidade, tornando as diferenças mais graduais.

Neste contexto, lembra-se da demolição do elevado da Perimetral do Rio de Janeiro (2014), um marco de um modelo de urbanização já superado, que conta com exemplos de reformulação desses espaços em vários locais do mundo. Sua discussão esbarra na revitalização de centros históricos, locais outrora nobres, em posições estratégicas, que agora sofrem com monumentos negligenciados e problemas sociais evidenciados por tráfico de drogas e pessoas sem acesso de qualidade à educação, saúde, moradia e trabalho.

A demolição do elevado figura como ação importante na operação urbana Porto Maravilha, que visa devolver a área portuária à cidade como uma região próspera, moderna, atraente. Estruturas elevadas viárias tendem a degradar o espaço em que são instaladas ao aumentarem níveis de poluição, tráfego de veículos, ruído, além de serem elementos já conhecidos pela "falta de segurança" (ou sua sensação) que provocam, devido à escuridão e ausência de pedestres na área. Toda a conjuntura levava a região a perder valor e confirmar um caráter de passagem, inseguro e incômodo à cidade. A demolição em prol de uma "nova cidade" parece um discurso válido, porém esbarra na questão de gentrificação, pois, no contexto de renovação urbana empreendida no local, tende a valorizar os imóveis da região e levar parte da população residente - geralmente de baixa renda -, a se mudar para regiões mais baratas por não conseguir arcar com o aumento dos preços. 
O High Line Park é um exemplo dessas renovações, feita em uma área degradada conferindo novo uso para uma linha férrea elevada desativada. Transformou-se em referência projetual no mundo todo, depois de valorizar o entorno e proporcionar à cidade um local de forte apelo cultural e de vivência urbana. Ali ocorrem performances artísticas, atuações, shows, exposições de obras de arte, grafite, dentre outras tantas atividades próprias do lazer cotidiano. As empenas cegas do entorno transformaramse em grandes telas para grafiteiros de diversas partes do mundo mostrarem seus trabalhos. Ao mesmo tempo, outras servem para anúncios publicitários serem divulgados. O parque prospera e tornou-se símbolo de um espírito urbano, de uma maneira "cool" de se experimentar a cidade (Figura 1). Por anos desativada, a linha férrea pôde ser transformada em parque graças à ação de uma associação de moradores e amigos do High Line, que visionaram ali um projeto paisagístico e cultural.

Mas essa solução não deve ser um carimbo para toda e qualquer estrutura viária em um entorno decadente. É preciso observar as particularidades de cada local. O Elevado Costa e Silva - o Minhocão, em São Paulo, por exemplo, é um assunto bastante polêmico e divide opiniões quanto a seu destino futuro. O projeto da década de 1970, de Paulo Maluf, construído para melhorar o trânsito da região leste a oeste da cidade, hoje é um símbolo da degradação de uma das áreas centrais da cidade e um divisor de águas em termos urbanos e sociais. De um lado, o bairro próspero de Higienópolis, do outro, a Água Branca, que sofre com violência, tráfico de drogas, edifícios históricos mal preservados. À noite e aos finais de semana e feriados, o Minhocão torna-se um parque, fechado aos automóveis. Há diversos projetos envolvendo o local: desde propostas arquitetônicas de transformação do mesmo em parque permanente, até intervenções artísticas pontuais, como grafites (cada vez mais comuns nas estruturas de concreto) e instalações temporárias, que dialogam com a dupla função do elevado, em suas esferas de tráfego e lazer, como a piscina proposta pela arquiteta Luana Geiger em 2014, como parte da Bienal de Arquitetura em São Paulo (que incitou a permanência e participação) ou as 
projeções em empenas cegas do "Festival Chave do Centro", de 2017 (que contribuíram para a estética do local, porém convergiam para a observação passageira, linear).

Interessante, entretanto, notar como a superfície de contato se dá de forma diferente entre o High Line e o Minhocão. No primeiro, a maior parte dos edifícios que estabelecem um contato direto com o elevado o faz por empenas cegas: daí a transformação das mesmas em telas urbanas, em obras de arte por grafiteiros. Já no segundo, há muitas fachadas frontais adjacentes ao viaduto. Neste caso, a privacidade é perdida e um uso residencial que já é difícil frente a veículos em movimento parece ainda mais descontextualizado frente indivíduos que utilizariam o local como espaço de permanência e vivência. Outra questão é a parte de baixo dos viadutos. O High Line, por não estar confinado a uma rua com edifícios dos dois lados e ainda ter partes em que não há quaisquer edifícios à sua margem, não enfrenta tanto o problema de sombreamento da parte inferior, permitindo que outras atividades se desenvolvam ali de maneira normal. O Minhocão, entretanto, possui quase todo o seu trajeto ladeado por edifícios, paralelos a ele, o que torna a entrada de luz na parte inferior do viaduto praticamente impossível.

Outro aspecto importante é o contexto econômico social do entorno. No High Line, a região vinha há anos recebendo novos serviços e constituindo-se como novo polo empresarial, cultural da cidade. O SOHO, nas proximidades, havia passado de um bairro decadente na década de 1950 para um local boêmio e procurado pelas classes mais altas já na década de 1970. Os artistas que ali se estabeleceram em busca de alugueis mais baratos mudaram-se já na década de 1990 com o aumento dos preços devido a uma valorização do bairro causada, ironicamente, por sua própria chegada (Lynch, 2011). Muitos desses artistas acabaram indo para West Chelsea, bairro cortado pela estrutura há anos desativada do High Line. Em 2005, foi aprovado um novo zoneamento para a região (City of New York, 2005), que incentivou novas construções de alto nível, ao mesmo tempo em que previa habitações de interesse social subsidiadas pelo governo. Quando, em 2004, foi proposto o Concurso de 
Projeto para transformar o High Line, a região já vinha se transformando para tornar-se um novo centro comercial e empresarial na cidade. $\mathrm{O}$ projeto vencedor de James Corner Field Operations e Diller Scofidio + Renfro, construído em 2009, tornou-se então referência mundial em renovação urbana e paisagismo.

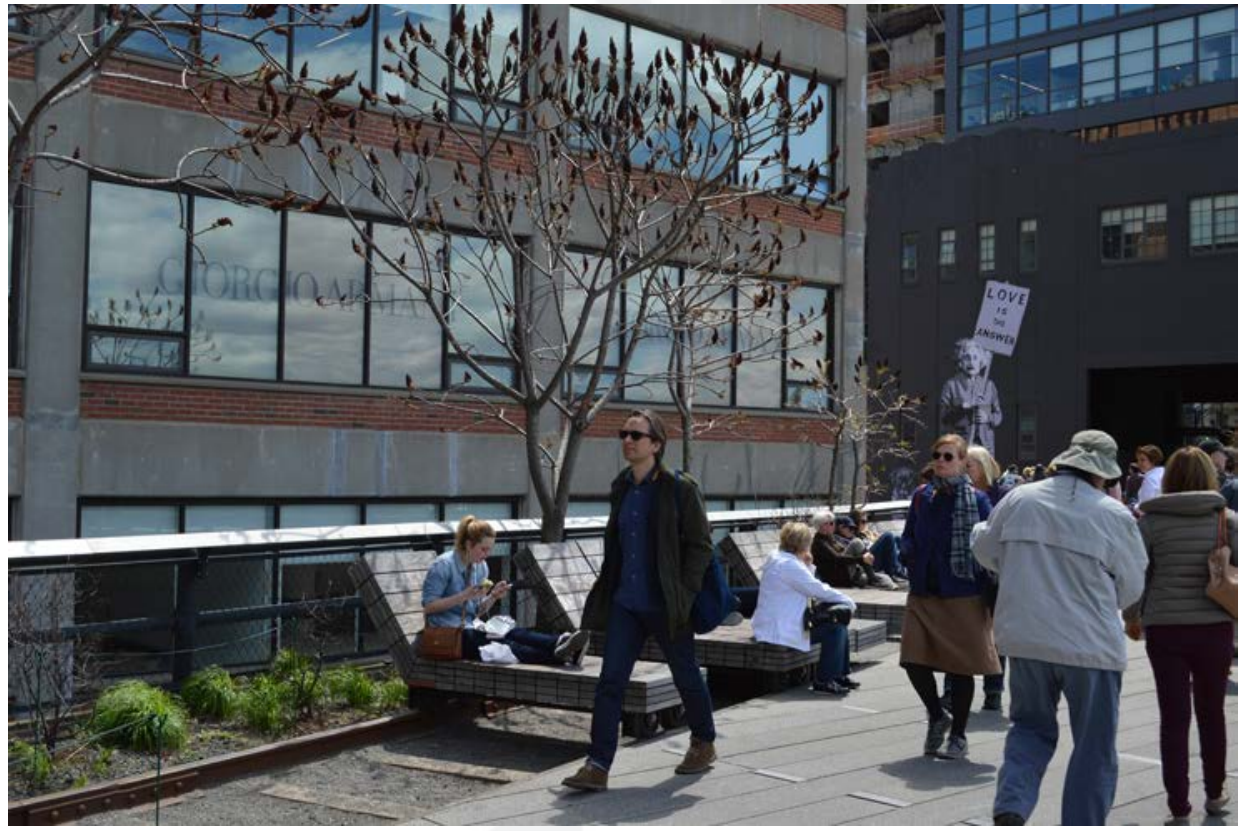

Figura 1: High Line Park em Nova lorque, em 2015. Os trilhos mantidos relembram a antiga função da estrutura. Em determinados pontos do percurso, as fachadas dos edifícios tornam-se murais artísticos ou outdoors publicitários - a realidade urbana codificada em imagens e símbolos. Foto do Autor

No caso do Minhocão, a região central de São Paulo ainda sofre com inúmeros problemas. Se, por um lado, os bairros de Higienópolis, Consolação e Santa Cecília possuem uma efervescente vida cultural, com universidades importantes rodeadas de intensa vida estudantil, restaurantes e lojas de médio-alto padrão, por outro, o centro continua sofrendo com suas ruínas, o conflito entre vida cultural e a tão questionada segurança, edifícios aos pedaços e a falta de um uso misto por diferentes grupos sociais em diferentes períodos do dia. Algumas ações recentes parecem colocar-se no intuito de transformar essa região, aos poucos, em local de maior permanência desses diferentes grupos, como a inauguração do Teatro Porto Seguro nos Campos 
Elísios (não sem críticas). O potencial da região como local de pulsão urbana e cultural vem sendo redescoberto gradativamente por pequenas iniciativas, coletivos e escritórios criativos, como estúdios de design, redações, oficinas de teatro, galerias de arte, estúdios de estilistas, artistas plásticos e grafiteiros (Cella, 2015, p. 132--40), atraídos pelos baixos preços, diversidade cultural e proximidade ao transporte público. Entretanto, a falta de serviços adequados ainda é um dos muitos problemas: internet e eletricidade são comprometidas nos edifícios antigos, algo primordial no atual "cybermundo". Essa "retomada" do centro que começa a engatinhar em São Paulo parece distante da conjuntura existente em West Chelsea quando a antiga linha férrea elevada foi reinaugurada como parque. Para o Professor da FAU-USP Lúcio Gomes Machado (apud Lamas, 2014), as situações são diferentes; “o projeto novaiorquino atendeu uma demanda conforme a cidade se expandia em serviços e habitação de alta renda. É uma escala diferente da que você vê em relação à Avenida São João".

A opinião pública a respeito da manutenção ou demolição do Minhocão é dividida e curiosa: uma reportagem de maio de 2015 do jornal Folha de $S$. Paulo afirmou que dentre aqueles favoráveis à demolição estava a maioria dos moradores e comerciantes locais (Sant'anna \& Tomé \& Gallo, 2015). O restante une-se a arquitetos, fotógrafos e advogados para defender a transformação da estrutura em parque. Uma pesquisa de setembro de 2014 feita pelo Datafolha indicava que $23 \%$ dos entrevistados desejavam que 0 Minhocão fosse transformado em parque, enquanto 7\% pediam a demolição; os outros ou defendiam a manutenção da via para os automóveis (53\%) ou não souberam opinar (17\%) (G1 São Paulo, 2014). Entretanto, essa última pesquisa não ouviu somente usuários e moradores da região, mas sim o "paulistano" em geral. Assim, a opinião cresce dividida entre aqueles que vislumbram um modelo americano/europeu de lazer (baseados no High Line de Nova lorque como principal referência), defendendo o já clichê arquitetônico "ocupar o espaço público", nem sempre inseridos diariamente naquela realidade, e 
aqueles mais afetados por qualquer intervenção ou ação sobre o elevado - a população local -, que, aparentemente, o enxerga mais como um entrave do que como uma solução. Se a construção do Elevado Costa e Silva no passado foi fruto de uma decisão unilateral pelo governo, sem contar com debates com a população da região para discutir os impactos da obra, espera-se que qualquer atitude tomada em relação ao futuro desta estrutura não repita a mesma ausência de participação popular. Ouvir os principais atingidos por qualquer obra de intervenção a ser feita no local é primordial para garantir uma cidade participativa, essa sonhada cidade de "fricção social". O Minhocão, como "interface" na cidade, tem seu sentido alterado de acordo com os grupos sociais que se envolvem com ele: aqueles que o frequentam quando os carros são proibidos experimentam uma dimensão de entretenimento do local - uma superfície de contato enaltecida, comparada a exemplos de sucesso semelhantes em outros países, uma experiência bastante marcada pelo "ver e ser visto" a que Fernanda Bruno se refere, elevada à esfera do cool; em oposição, tem-se aqueles que moram nos inúmeros apartamentos que faceiam a estrutura: estes experimentam a exposição nem sempre desejada, obtendo uma superfície de contato extremamente pulsante e inevitável - o "ver e ser visto" não necessariamente de maneira positiva. Assim, observa-se que não só a conjuntura existente entre o High Line e o Minhocão é bastante distinta, mas os processos envolvendo o entendimento da cidade como superfície de contato para diferentes grupos também o são. Enquanto a iniciativa de transformação do High Line em parque surge a partir de uma associação de moradores, no Minhocão ela surge a partir de uma associação primeiramente desvinculada à população local, com ativistas e arquitetos em sua composição. Além disso, o mercado nova-iorquino aproveitou o momento de incentivos a novos empreendimentos no local causado pela nova medida do plano diretor, enquanto que em São Paulo, apesar dos incentivos dados para se investir no centro já há alguns anos, através da Operação Urbana Centro e de outros planos, como o "Plano Reconstruir o Centro" do PROCENTRO e da Administração Regional da Sé (Nobre, 2009), a área continua ainda sendo vista com pouco interesse pelo mercado imobiliário. 
Trata-se de uma conjuntura também bastante diferente daquela encontrada no entorno da perimetral do Rio de Janeiro. A demolição da estrutura de fato concretizou maior integração dos monumentos históricos aos espaços públicos revitalizados, como a Praça Mauá (Figura 2) e a Praça da Candelária. A implementação do Veículo Leve sobre Trilhos (VLT), conectando importantes pontos do centro, interessante especialmente aos turistas (que respondem por grande receita da cidade), juntamente à construção de túneis em substituição ao elevado configura uma nova escala de cidade ${ }^{2}$, perceptível ao nível da rua. A construção de novos empreendimentos no local em curso, porém ainda lenta frente um cenário econômico incerto, transformará a imagem do local. Entretanto, a integração das estruturas antigas com as novas depende de outras questões não somente atreladas à forma física urbana, como trabalhos sociais e mecanismos de garantir permanência de moradores e estabelecimentos locais. Apesar de essas renovações urbanas aproximarem-se do que Harvey denomina "propostas capitalizadas", isso não muda o fato de serem necessárias. Como realizá-las de maneira a unificar os espaços ao invés de segregá-los, convertendo uma "arquitetura do medo" em uma arquitetura da participação, do envolvimento, é ainda um desafio, no entanto.

\footnotetext{
2 Próxima aos discursos de "cidades para pessoas", como exaltado por Jan Gehl (2013), por exemplo, mirando-se na pedestrianização de ruas e conversão de espaços urbanos motorizados em espaços de permanência públicos.
} 


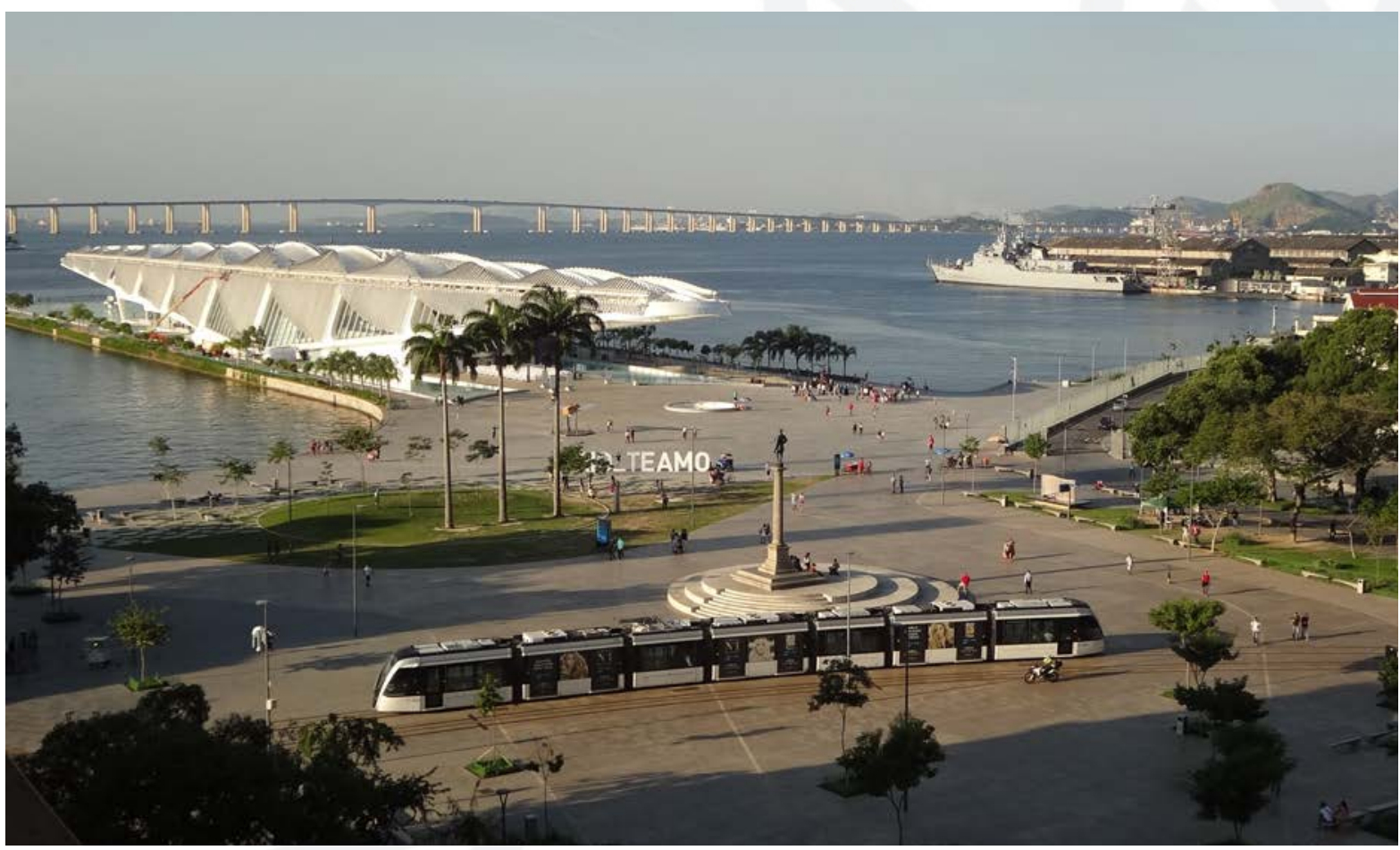

Figura 2: Praça Mauá, no Rio de Janeiro, nova superfície de contato urbana após demolição do elevado da perimetral. Ao fundo, o Museu do Amanhã, de Santiago

Calatrava. Foto do Autor

\section{CIDADES DA VIGILÂNCIA E DO ESPETÁCULO: APARÊNCIAS E}

\section{EVIDÊNCIAS}

Essa arquitetura do medo remete ao texto de Paul Virilio, "The Administration of Fear" (2012), em que o autor comenta sobre uma aceleração do nosso tempo, uma contração do espaço-tempo, que leva ao medo contemporâneo. Esse medo, extremamente relacionado à velocidade com que as coisas passaram a acontecer, retoma a ideia do panóptico de Michel Foucault, por meio da qual se impõe um sistema onipresente de vigilância. As novas relações que o indivíduo estabelece com o meio valendo-se dessa realidade aumentada, do "cyberespaço", produzem o panóptico também expandido, isto é, sem barreiras físicas. Somos vigiados e controlados de qualquer lugar em que estejamos, seja por equipamentos de vigilância como câmeras, seja por nossos celulares, aplicativos ou computadores. 
Mais do que isso, com a licença de deturpar a expressão foucaultiana, podemos dizer que estamos na era do "pan-óptico": nossos olhos vão de uma imagem a outra muito rapidamente, como o movimento de "pan" do computador. Se antes o panóptico era o mecanismo máximo de controle da sociedade, hoje, este é exercido pelo conjunto de imagens que estão presentes em todo lugar de nossa vida moderna. Ao mesmo tempo, o medo que sentimos também se manifesta nesse movimento rápido dos olhos: precisamos constantemente olhar para o que vem por trás de nós, pelos lados... Presenciamos uma série de fatores que nos fazem sempre precisar desse "pan", desse movimento rápido quase automatizado. Da mesma maneira, a sociedade tecnológica vigia tudo e todos em alta velocidade com seus olhos virtuais.

É interessante também atentar para outra ideia de Virilio: a ideia dos equipamentos como próteses da visão, que não nos permitem enxergar com totalidade e verdade. Há um conflito entre aparência/evidência, entre a superfície de contato e o contato em si. A ideia de um olhar "pan-optizado" que ao mesmo tempo não permite enxergar com verdade relembra um filme sci-fi da década de 1980, "Eles Vivem" ("They Live”, no original), de John Carpenter. No filme, nosso planeta é invadido por alienígenas, que o controlam por meio de diversas mensagens subliminares, ocultas em propagandas e outras inscrições em meios midiáticos, as quais só podem ser decifradas utilizando-se de um par de óculos de sol especial. Uma cena emblemática mostra o protagonista com os "óculos da verdade" ao caminhar pela cidade, através do qual ele pode ver a "evidência" de todas as "aparências" do espaço em que vive, tomando consciência de sua posição passiva e controlada: os signos são convertidos em significados escancarados, outdoors publicitários transformam-se em mensagens claras e imperativas, intrínsecas às imagens de caráter sexual, indutoras de consumo e obediência. Tais imperativos reforçam a mensagem que todas as escrituras urbanas e signos desejam passar; mensagens subliminares cada vez menos sutis e mais escancaradas, ao passo que os indivíduos estão cada vez mais cegos e distantes. 
Essa distância do indivíduo e a supremacia da aparência frente à evidência comumente são apropriadas por projetos de renovação urbana e valorização de regiões decadentes. Não raro, a arquitetura assume papel primordial nesse processo de reinterpretação e ressignificação urbana; atrelada ao espetáculo, como em museus com projetos grandiosos, transita entre o valor de uso e o valor de troca de espaços urbanos. O High Line, por exemplo, teve em maio de 2015 a inauguração do mais recente museu de Renzo Piano em sua proximidade, corroborando o novo caráter cultural, bourgeois-boheme do local.

Outro exemplo relevante nesta discussão é o Museu do Amanhã, na região portuária do Rio de Janeiro, uma iniciativa ambiciosa da Prefeitura do Rio de Janeiro e Fundação Roberto Marinho com o Banco Santander (patrocinador máster), que recebeu projeto do renomado, porém controverso, arquiteto espanhol Santiago Calatrava, conhecido já por suas estruturas de grandes dimensões e formas inusitadas. O museu, focado no futuro das cidades e da sociedade, tem uma curadoria baseada em dispositivos midiáticos e uma proposta de interatividade com o espectador. O papel do museu de expor a história é reformulado de maneira a apresentar o futuro, o amanhã. Tal papel é refletido na arquitetura extremamente tecnológica (apesar do projeto expográfico ser bem mais tímido neste quesito), ao mesmo tempo em que a construção se torna um marco para a paisagem e um atrativo econômico da região. Possuir um "Calatrava" traz status para a cidade, podendo impulsionar novas construções e projetos no entorno. Entretanto, o furor causado pela renovação da área portuária vem acompanhado da já mencionada questão da gentrificação, da diferença no trato das diferentes áreas abrangidas pela operação $^{3}$, das implicações da alteração no traçado urbano nas dinâmicas

\footnotetext{
${ }^{3}$ As áreas mais próximas à primeira fase de intervenção e à orla da Baía de Guanabara, próximo à Praça Mauá e ao Boulevard Olímpico, recebem mais atenção e interesse tanto do público quanto dos investidores privados, já sendo vistos alguns novos edifícios no skyline portuário, de arquitetos consagrados internacionalmente como Norman Foster.
} 
locais ${ }^{4}$. Inaugurado em dezembro de 2015, o museu é um sucesso de visitações. Com a inauguração do Boulevard Olímpico durante as Olimpíadas do Rio de Janeiro, em agosto de 2016, o museu pôde, enfim, ver-se integrado à Praça Mauá, onde se localiza também o Museu de Arte do Rio (MAR), além de pertencer a um novo ponto turístico da cidade na forma de uma promenade linear ao longo da Baía de Guanabara. Apesar de ser um catalisador de regenerações urbanas, a arquitetura icônica, por si própria, não é capaz de inverter a lógica existente em um local. Apenas com investimentos concentrados, debates com a população e um trabalho de integração do existente ao novo é que a cidade pode se regenerar. Assim, a interatividade proposta para o interior do edifício do Museu do Amanhã deve ocorrer também no exterior: cidade e edifício devem entrar em relação de simbiose, de forma que o edifício participe da cidade e esta participe do edifício. o visitante não deve se posicionar ante somente uma aparência, mas sim ante todo o significado que tal objeto visa passar, seja ele um momento histórico, uma possibilidade de um futuro, uma nova superfície de contato com a cidade. Entretanto, o que existe por trás das obras - implicações políticas, econômicas, sociais -, acaba sendo desviado da atenção pública pela exaltação de se ter uma obra arquitetônica deste porte em uma das cidades mais importantes do país, fazendo com que o visitante geralmente se coloque numa posição de espectador imóvel, passivo.

De fato, as novas demandas urbanas impõem uma posição maior que simplesmente a de espectador interativo, mas sim a de um espectador participativo, que busque soluções e mudanças, que crie pontos de conflito em suas ações e reações. A arquitetura do espetáculo está repleta de interatividade, porém Ihe faltam acesso e participação.

\footnotetext{
${ }^{4}$ Por exemplo, funcionava na Praça Mauá o Terminal Rodoviário Fluminense, gerador de fluxos na região. Como constatado em visita e pesquisa de campo com estabelecimentos locais em maio de 2017, a saída do terminal alterou algumas dinâmicas no setor terciário local.
} 
O papel do espectador emancipado, como afirma Jacques Rancière, é o de traduzir e contra traduzir aquilo com o qual se depara, de associar e dissociar informações. Apesar de Rancière referir-se ao teatro para exaltar a emancipação do espectador, transpõe-se essa emancipação também para a vida cotidiana, em que todos são espectadores de um grande cenário urbano. Rancière afirma que "olhar é o contrário de conhecer", no sentido que o espectador permanece ante uma aparência, ignorando o processo de produção dessa aparência ou a realidade que ela recobre; e que "olhar é o contrário de atuar", enfatizando a posição imóvel, passiva do espectador. Para ele, essa relação deve ser quebrada, num teatro em que a ação é levada a sua realização por corpos em movimento frente a outros corpos vivos que se mobilizaram. Para ele, é necessário um teatro em que os concorrentes aprendam ao invés de serem seduzidos pelas imagens, em que se convertam em participantes ativos ao invés de voyeurs passivos (Rancière, 2010). A emancipação, para Rancière, está intimamente ligada à superação da separação entre sala (plateia) e cena (palco). Afirma:

A finalidade da performance consiste em suprimir de diversas maneiras esta exterioridade - pondo os espectadores sobre o cenário e os performers na sala, suprimindo a diferença entre um e outro, deslocando a performance a outros lugares, identificando-a como a tomada de posse da rua, da cidade ou da vida. (Rancière, 2010, p.21)

\section{A PERFORMANCE E A CIDADE, O CORPO E O ESPAÇO:}

\section{REALIDADES E EXPANSÕES}

Uma performance interessante que se relaciona com o espaço urbano é a da artista britânica Cally Spooner, encenada no já comentado High Line Park (Friends of High Line, 2014). Girando em torno de um produto fictício chamado "It's about you", a performance baseia-se em vídeos projetados ativados por atuações concomitantes por cantores de ópera, que comunicam a linguagem dos anúncios publicitários como se fossem "libretos". 
O projeto explora diferentes ideias sobre a questão da extração de dados pessoais para a esfera pública, misturando dança, canto e a linguagem escrita exibida nas telas, retirada de uma série de feeds do Twitter contendo a hashtag "\#prism", que contestavam o Programa de Vigilância da Agência Nacional de Segurança dos Estados Unidos (NSA Surveillance Program) e a extrapolação/assédio em pegar informações pessoais e colocá-las em domínio público. Spooner explica que as hashtags acabaram sendo confundidas com outra igual utilizada para divulgar o álbum de verão da cantora pop Katy Perry de 2013 de mesmo nome, transformando o libreto em uma coleção extremamente caótica de tweets: uma parte, posicionamentos políticos a fim de reclamar pela privacidade novamente; a outra, comentários de fãs eufóricos da cantora em êxtase pelo novo álbum.

A utilização de cantores de ópera na performance deve-se a uma crítica à dramatização das redes sociais e do mundo regido por elas. Os cantores atuavam como se estivessem em um relacionamento amoroso com a tela, intercalando paixão e desespero ao comunicar os feeds - inscrições nesses espaços de realidade expandida, onde a vida pessoal, os desejos e as ações são "atuadas" de maneira bastante dramatizada no espaço público (aqui entendido como este espaço cíbrido, conectado pela virtualidade dos espaços das redes sociais).

Assim, a performance atinge diferentes aspectos relativos às implicações desta expansão da realidade, dessa imbricação entre o mundo físico e o espaço virtual, do online e off-line. Abrangendo uma das principais preocupações do homem pós-pós-moderno, a questão da vigilância, coloca em pauta o papel das redes sociais como vetor de transmissão de informação incontrolável, uma ferramenta em massa de vigilância. A ideia do panóptico de Virilio é revertida para o "sinóptico", termo cunhado por Thomas Mathiesen, em que o controle da visão não mais é exercido por um único organismo, mas por vários, num processo de renovação da face política, estética e tecnológica do antigo espetáculo das sociedades de soberania (Bruno, 2013, 46). 
Voltando ao caso da renovação urbana no Porto Maravilha, tem-se ainda como exemplo interessante do espetáculo coletivo na interface cidade-virtualidade as selfies em frente aos murais de grafite encomendados para animar as fachadas antes deterioradas dos galpões portuários durante os Jogos. O maior e mais famoso deles, o mural Etnias (Figura 3), realizado pelo artista Kobra, que também possui uma obra no High Line, foi recorde de fotografias e selfies durante o megaevento. Curioso, entretanto, que outros painéis tão interessantes quanto, como o que retratava atletas refugiados próximo ao Aquário, não tiveram a mesma popularidade. Comissionado pela prefeitura e parte de um circuito de arte de rua no centro do Rio de Janeiro promovido pela rede social Instagram durante os Jogos ("Instawalk Rio") que encorajava os visitantes-espectadores a postarem suas fotos em frente às obras utilizando a hashtag, tal exemplo parece uma das respostas contemporâneas ao cruzamento de dados com o espaço público. Uma ação que, no entanto, evidencia o caráter interativo do espectador, ao invés de participativo, que utiliza a arte como interface para sua visibilidade. Ao mesmo tempo, tal ação suscita questionamentos sobre as intenções subjacentes: seria essa uma maneira de divulgação ou vigilância? Um interesse na renovação urbana ou na promoção da imagem?

O "ver e ser visto" de Fernanda Bruno torna-se aqui elevado ao máximo pelas postagens na rede social com uma hashtag em comum, promovendo e divulgando tanto a obra quanto o indivíduo em seu núcleo de amizades virtuais, além de criar um posicionamento simbólico por estar presente no local. Por outro lado, o mecanismo da hashtag controla e mapeia o valor de cada obra pela quantidade de sua aparição, assim como os gostos e preferências dos usuários, podendo, portanto, ser inserido em um contexto de vigilância e monitoramento. No sentido da vigilância, outro viés possível a ser analisado é a questão de fachadas atraentes propiciarem maior confluência de pessoas e mesmo induzirem à sua permanência nas proximidades, ao contrário de extensas fachadas cegas e deterioradas que sugerem abandono e ausência, inibindo vida urbana diversa e vibrante em sua imediação. De qualquer modo, 
ressalta-se que, uma vez que os grafites por si só não são promotores de regeneração em longo prazo, cabe à operação urbana a continuidade dos planos prometidos para a região.

$\mathrm{Na}$ internet, todos veem e são vistos e o fazem intencionalmente. Assim como na performance de Spooner, as ações tornam-se dramatizadas, quase teatrais. Segundo Bruno (2013, p. 70): "Nas práticas em questão, o lugar onde o "eu" se realiza e se efetiva é na proximidade do olhar do outro, na sua potencialidade de ser visto, e não tanto no recolhimento de uma interioridade relativamente opaca". E, ainda, "Ver e ser visto não implica apenas circuitos de controle, mas também de prazer, sociabilidade, entretenimento, cuidado consigo e com o outro" (Bruno, 2013, p. 67). Há uma exaltação na relação do indivíduo com a tela, com esse dispositivo eletrônico que o conecta com outros espaços, outros indivíduos, que expande sua realidade e o coloca em estado de simbiose com a superfície e, mais profundamente, com a nuvem. Uma exaltação com efeitos similares à espetacularização, em que espectadores são extremamente dependentes de uma relação pré-definida com o objeto; no caso das redes sociais, já há um código de conduta específico para se ter ou não sucesso no espaço virtual e não cabe a ninguém expressar a verdade "nua e crua". A internet da socialização é feita para aparências, não para evidências. 


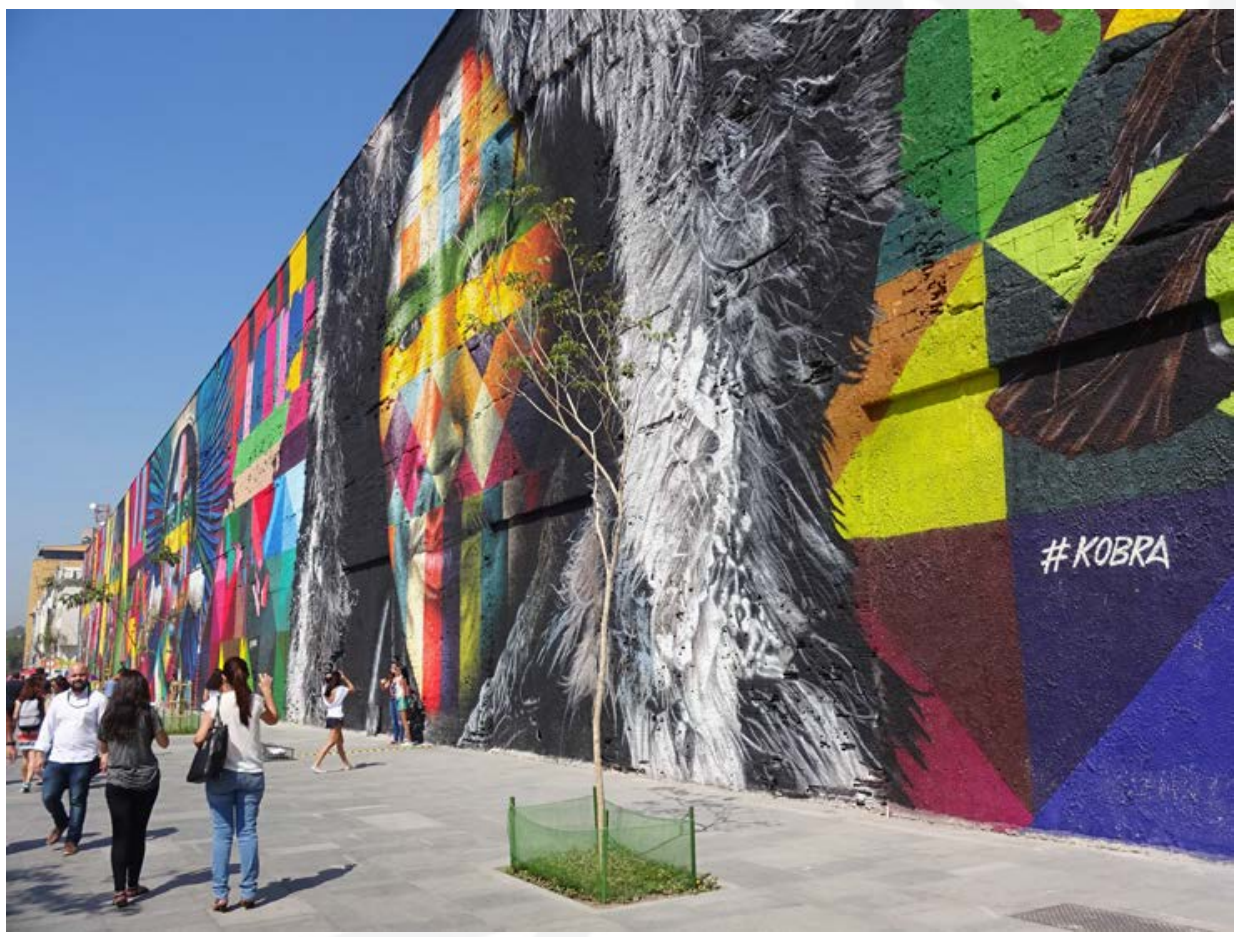

Figura 3: Mural Etnias em agosto de 2016, durante os Jogos Olímpicos do Rio. O “ver e ser visto", como discutido por Bruno (2013), desponta nas selfies e compartilhamentos online em frente à obra. Foto do Autor

\section{CONCLUSÃO}

As transformações empreendidas nas três estruturas urbanas analisadas - o High Line, o Minhocão e a demolição da Perimetral no Rio - evidenciam diferentes exemplos de relações com o conceito de "cidade como interface" e com o cruzamento de dados no espaço físico e virtual. Apesar da globalização da vivência urbana, com imagens, códigos e dispositivos semelhantes, atentase para as particularidades de cada local, que influenciam no modo como os espaços urbanos são usufruídos e a vivência urbana consolidada.

No caso do High Line, observa-se que o estágio avançado da cidade de Nova lorque em direção ao status econômico e cultural global proporcionou, juntamente a um processo gradual de transformação do entorno da região em polo boêmio e artístico e à vontade da comunidade envolvida, a conversão da estrutura em um parque de alto padrão, que se retroalimenta das condições 
que the promoveram e concederam seu sucesso. O novo valor de uso da estrutura férrea desativada, voltado às demandas globais inseridas num circuito de prazer e entretenimento, para lembrar Bruno (2013), ainda que capitalizado (como diria Harvey), tem se mostrado favorável à consolidação da nova imagem do bairro e à criação de vivências urbanas coletivas (ainda que fortemente pautadas em aspectos interativos e de visibilidade midiática, como é próprio da sociedade atual). No caso do Minhocão, seu valor de uso dual como parque ou via expressa em períodos distintos - é conflitante. A ambiguidade das funções reflete nas intervenções artísticas no local: enquanto a piscina de Luana Geiger propiciou um espaço de permanência, convívio, interação e participação da população usuária do local como lazer, incentivandoa a ocupá-lo e adotá-lo como seu, ainda que transitoriamente; outras instalações, como exposições fotográficas nos pilares do elevado ou as projeções em movimento nas empenas cegas no período noturno do "Festival Chave do Centro", focaram, ainda que no aspecto estético e de percepção da via como algo além das superfícies de concreto, no usuário transeunte, que passa pela estrutura, mas não participa da mesma, apenas interage com as telas que the são mostradas. No entanto, as projeções nas fachadas servem como importante resposta à perda da visão lateral gerada pela velocidade do tempo contemporâneo, como discutido por Virilio (2012, p.37), uma vez que força o indivíduo a se deter um instante para apreciar o que lhe é mostrado, num eixo diverso daquele de seu percurso habitual e automático. Neste sentido, tais intervenções também incentivam novas maneiras de se perceber as superfícies da cidade, podendo gerar frutos importantes para sua utilização posterior.

No exemplo da remoção da Perimetral do Rio, também se tem uma mudança de relação entre usuários (atraindo novos perfis, inclusive) e ambiente construído, resultante principalmente da nova arquitetura e dos usos propiciados pelas mesmas (cultura, encontro, etc.). Tanto o Museu do Amanhã quanto o mural "Etnias" discutidos introduzem novas imagens no espaço urbano e incentivam novas maneiras de percebê-lo. Em relação ao último, destaca-se que as superfícies de contato ali, no entanto, se 
pautadas apenas na interação visual ou fotográfica, não contribuirão para um valor de uso pleno à área.

A cidade, cuja evolução e transformação são constantes, inevitáveis e inclusive desejáveis, é feita de um entrelaçamento de forças, entre o que vê e o que é visto, entre o que controla e o que precisa ser controlado, entre o que existe e o que será feito, entre outras tantas dualidades. Quando as forças são dirigidas para um bem comum, entretanto, aí a cidade pode ser entendida como uma superfície de contato plena, uma fusão entre o "cyberespaço" e o espaço físico, entre as diferentes realidades que frequentamos.

\section{BIBLIOGRAFIA CITADA}

BRUNO, F. Máquinas de Ver, Modos de Ser: Vigilância, Tecnologia e Subjetividade (2013). Porto Alegre: Sulina (coleção Cibercultura).

CELLA, L. De Volta ao Centro (2015). Arquitetura e Construção. Editora Abril. Ano 31, no 4, p. 132-140.

HARVEY, D. The creation of Urban Commons. In: HARVEY, D. Rebel Cities (2012). Brooklyn, NY: Verso.

RANCIÈRE, J. El Espectador Emancipado. In: RANCIÈRE, J. El Espectador Emancipado (2010). (Tradução de Ariel Dilon. Revisão de Javier Bassas Vila. p. 7-29). Vilaboa (Espanha): Ellago Ediciones.

VIRILIO, P. The Administration of Fear. (2012). Tradução de Ames Hodges. Semiotext(e). MIT Press

\section{Fontes eletrônicas e sites}

CITY OF NEW YORK. West Chelsea Zoning Proposal (2005). New York City Planning. Department of City Planning. Disponível em: <http://www.nyc.gov/html/dcp/html/westchelsea/westchelsea3a.shtml >. Acessado em 26 de junho 2015.

LAMAS, J. Afinal, o que será do Minhocão? (2014). Planeta Sustentável. Disponível em: <http://planetasustentavel.abril.com.br/blog/urbanidades/afinal-o-quesera-do-minhocao/>. Acessado em 24 de junho de 2015. 
NOBRE, E. A. C. Políticas Urbanas para o Centro de São Paulo: Renovação ou Reabilitação? Avaliação das Propostas da Prefeitura do Município de São Paulo de 1970 a 2004 (2009). Pós V.16 N.25. São Paulo.

G1 São Paulo. Paulistanos são contra demolição do Minhocão, diz Datafolha (2014). Disponível em: <http://g1.globo.com/saopaulo/noticia/2014/09/paulistanos-sao-contra-demolicao-do-minhocaodiz-datafolha.html>. Acessado em 29 de junho 2015.

LYNCH, M. Soho - From Boho to Bobo: The Business Establishments of West Broad-way. [Tese de Mestrado] Nova lorque (EUA): The City University of New York, Graduate Faculty in Liberal Studies, Master of Arts; 2011. Disponível em: $<$ https://sohomemory.files.wordpress.com/2012/03/thesiswebversionja n12.pdf>. Acessado em 29 de junho 2015.

O Globo. Arquiteta monta piscina de 50 metros no Minhocão, em SP. Disponível em: <https://oglobo.globo.com/brasil/arquiteta-montapiscina-de-50-metros-no-minhocao-em-sp-11961851 >. Acessado em 01 de fevereiro de 2018.

SANT'ANNA, E.; TOMÉ, P. I.; GALLO, R. Futuro do Minhocão opõe morador a ativista (2015). Folha de São Paulo. 23/05/2015. Disponível em: <http://www1.folha.uol.com.br/cotidiano/2015/05/1632817-futuro-dominhocao-opoe-morador-a-ativista.shtml>. Acessado em 29 de junho 2015.

ELES Vivem (“They Live”). John Carpenter. 93min. Ação, Comédia, Terror. 1988

FRIENDS of High Line (2014) High Line Art Presents Cally Spooner, It's About You. Disponível em: <https://www.youtube.com/watch?v=1QsYuYM3HUI>. Acessado em 29 de junho 2015. 